\title{
ProximIdAd POLICIAL EN CiUdAd JuÁREZ
}

\author{
RAFAEL VALENZUELA \\ JOAHO ACOSTA
}

\section{RESUMEN}

I n el marco de los modelos de policía de proximidad social,

— Ciudad Juárez enfrenta importantes problemas para imple-

1 mentar un modelo basado en un perfil adecuado. La premi-

sa del estudio sugiere que Ciudad Juárez requiere de un protocolo de actuación policial con características de proximidad hacia el ciudadano. Mientras no se definan objetivos precisos y medibles de seguridad ciudadana, la proximidad de la policía será solo un discurso sin resultados tangibles en la comunidad juarense. La elevada ola de violencia en Juárez, Chihuahua, y su radical disminución en pocos años, lo hace un caso digno de estudio.

Palabras clave: Seguridad pública, proximidad, policía y violencia

\section{INTRODUCCIÓN}

El presente capítulo se propone abordar los diferentes conceptos de seguridad para explorar el contexto de Ciudad Juárez. Actualmente la ciudad fronteriza está en proceso de instrumentar el modelo de policía de proximidad. Para el análisis, se desarrolló un marco teórico conceptual que facilitó conocer las condiciones bajo las cuales es posible lograr resultados positivos en seguridad pública y los retos que enfrenta a nivel local. La premisa del estudio sugiere que mientras en Ciudad Juárez no se diseñe y ejecute un protocolo de actuación policial con características de proximi- 
dad hacia el ciudadano, la transición del modelo tradicional hacia otro de proximidad será solo un discurso sin resultados tangibles en la comunidad juarense.

El contexto jurídico y político de la seguridad pública facilita la identificación del alcance y los objetivos de la transición de una seguridad pública caracterizada por un orden jerarquizado tradicional hacia una seguridad más ciudadana. La ola de violencia e inseguridad pública que vivió Ciudad Juárez lo hacen un estudio de caso digno de analizarse desde diversas disciplinas. Actualmente, es laboratorio de varios experimentos de intervención en prevención social y evaluación ciudadana de la seguridad pública, aún sin resultados determinantes en cuanto a un cambio de la percepción ciudadana, a pesar de los datos que este capítulo ofrece al lector.

\section{La seguridad pública en el contexto local, 2006-2016}

La comprensión de los vaivenes que presenta la seguridad pública en Ciudad Juárez requiere delinear un contexto formado por su historia reciente y las miradas de diversos actores a los fenómenos de violencia e inseguridad. El entramado de violencia que azotó a Ciudad Juárez destaca por dos momentos concretos: 1995-2005, el lamentable episodio caracterizado por los feminicidios ahora extendido al resto del país, y 2006-2016, una década conocida por la militarización de la policía y el posterior desarrollo de acciones contra la violencia y a favor de la prevención social del delito.

Partiendo del segundo momento, la policía de Ciudad Juárez sufrió un cambio radical en su mando operativo, decisión dictada desde la esfera federal con el objetivo de frenar la violencia. Se militarizó la actuación y el mando de la corporación local y poniendo en la lupa del mando de autoridades militares su actuación como policía local, cuya naturaleza está en el ámbito civil, con distinta vocación y entrenamiento para realizar su función policial. Todavía en la sociedad juarense, "el Estado y los grupos relacionados con el narcotráfico aparecen como una realidad anormal", lo que tiene un significado relevante en tanto que refie- 
re una falta de apropiación o normalización de esos fenómenos sociales (Oseguera, 2016).

Actualmente, la corporación de policía cuenta con alrededor de 2400 elementos, de los cuales alrededor de 300 han egresado bajo un modelo de agentes de proximidad (Constantino, 2016). Entre 2008 y 2016, los cambios en la corporación de policía implicaron un ejercicio de autoritarismo a tono de la guerra contra las drogas, donde la muertes de jóvenes en el fraccionamiento Salvárcar de Ciudad Juárez fue detonante de lo que venía aconteciendo en forma creciente: violencia, drogas, tráfico de personas y otros delitos que vienen a constituir toda una industria delictiva.

En la misma década 2006-2016, Ciudad Juárez destacó entre las 50 ciudades más violentas del mundo, dado el número de homicidios ocurridos en la localidad. ${ }^{1}$ De acuerdo con el reporte 2016 elaborado por el Consejo Ciudadano para la Seguridad y Justicia Penal, A.C., la ciudad de referencia dejó el rango de las 50 ciudades, al cual aludimos líneas arriba, cuando en el 2010 lo encabezó. El estigma de la ciudad más violenta del mundo no es nuevo. Anteriormente, "epítetos como 'la ciudad más perversa de América' fueron endilgados a Cd. Juárez en fechas tan tempranas como 1915, creándose la famosa leyenda negra sobre su estereotipo de 'ciudad perdida'” (Aguirre, 2014: 61, siguiendo a González, 2009: 148-149).

Entre 2010 y 2015, período que Ciudad Juárez encabezó el ranking y redujo su tasa de violencia de 229 homicidios por cada 100 mil habitantes a 39 por cada 100 mil habitantes en 2014, hasta la tasa actual, menor a 30 por cada 100 mil habitantes.

El cambio abrupto en la corporación, después de la etapa de militarización, implicó renovar procesos y estrategias, y poner en práctica nuevos enfoques de acercamiento a la comunidad.

No todo ha sido positivo en la etapa de reducción de la tasa de violencia basada en el número de homicidios. La caída económica derivada de la violencia ocasionó la expulsión de un número aún calculado con inexactitud, pero se estima en un $20 \%$, de la población de 2010. Juárez pasó de una dinámica industrial ma-

1 "Reporte de las 50 ciudades más violentas del mundo", elaborado por el Consejo Ciudadano para la Seguridad y Justicia Penal, A.C., publicado en 2015. 
quiladora, atractiva para migrantes nacionales y extranjeros, a una dinámica de expulsión de sus residentes.

Lentamente, la ciudad muestra su recuperación sin que implique echar campanas al vuelo. La policía ha sido un factor favorable, pero no el único y quizá no el más importante, en la reducción significativa al índice de ciudades violentas. La historia de las policías es un aspecto poco documentado en México, sin embargo, Juárez tiene una historia que lamentablemente estigmatizó, a la vez que visibilizó sus carencias y problemas de seguridad.

La corporación de policía transita hacia modelos más próximos a la comunidad juarense por presión de la sociedad organizada. Grupos, organizaciones, universitarios y otros actores sociales han impulsado el diálogo entre actores del gobierno, sociedad, empresa y universidad. La Mesa de Seguridad y Justicia de Ciudad Juárez ha sido un factor clave, el cual no es monolítico, sino actor heterogéneo con intereses diversos pero un mismo propósito: elevar la calidad de la seguridad pública e incentivar una ciudadanía de alta intensidad en la toma de decisiones en seguridad. Los indicadores de la mesa confirman la reducción de la violencia antes provistos, pero mantienen la atención acerca de cierta tendencia a la alza, como se ilustra en la imagen: 
Imagen 1. Número de homicidios por mes

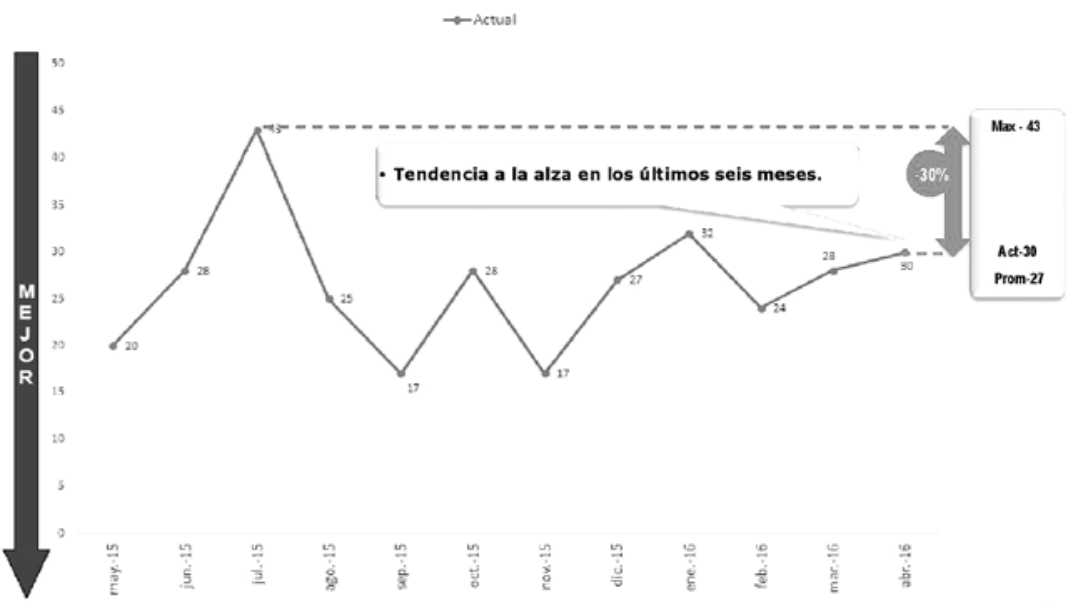

Fuente: Sitio web de la Mesa de Seguridad y Justicia de Ciudad Juárez, AC. (http://www.mesadeseguridad.org/wp-content/uploads/2016/05/Indicadores-Mesa-de-Seguridad-Abril-2016-page-004.jpg)

Durante 2015 y 2016, la corporación de policía en Ciudad Juárez se sometió a un proceso de certificación policial (Certipol), cuya metodología fue implementada por el Instituto de Seguridad y la Democracia, A.C. (Insyde), cuya coordinación de apoyo en Ciudad Juárez estuvo a cargo del Fideicomiso para la Competitividad y Seguridad Ciudadana (Ficosec). El proceso de certificación estuvo validado por un Comité Ciudadano cuyos integrantes tienen origen diverso y plural. Con base en la revisión de 54 estándares, el Comité Ciudadano verificó el cumplimiento objetivo de todos los criterios establecidos en el proceso certificador.

Independientemente del resultado obtenido, que se dio a conocer en julio de 2016, el proceso en sí mismo tiene implicaciones relevantes para la seguridad pública y representa uno de los pasos a seguir hacia el modelo de policía con énfasis en la proximidad, eficiente en su operación y que cumpla estándares mínimos de una policía municipal en México. Este proceso de certificación es una forma de control social que fortalece la rendición de cuentas de las corporaciones de policía en México. 
Cuando la policía recuperó el control civil y dejó el mando militarizado, parece haber ingresado en una etapa de regeneración y replanteamiento de la manera en la cual ejerce sus funciones. Cumplir un estándar de carácter administrativo de ninguna manera representa una corporación exenta de fallas, violaciones a derechos humanos y resultados insatisfactorios, sino que es la oportunidad de proponerse mejorar a partir de un monitoreo independiente.

En suma, la etapa de violencia en Ciudad Juárez se distingue por los feminicidios y la militarización del mando policiaco. En la etapa de postviolencia se tienen dos momentos clave: la recuperación del mando civil para una corporación de naturaleza civil y ejercicios de control social para una policía que desea el enfoque de proximidad a comunidades y ciudadanos. La recuperación del mando civil requerirá de resultados tangibles, mientras que la apertura hacia la participación de actores sociales clave en materia de seguridad implicará un cambio de cultura organizacional de la policía y cumplimiento sostenido de procedimientos y protocolos establecidos en la ley.

La creación de un protocolo de seguridad para sentar las bases de la proximidad será uno de los retos que se aborden en este capítulo del libro.

\section{Bases de la discusión conceptual}

Al abordar temas sobre seguridad confundimos o empleamos indistintamente algunos términos como seguridad nacional, seguridad pública y seguridad ciudadana. Cada uno de estos conceptos tiene un significado diferente en el marco de las responsabilidades que le competen al Estado y la sociedad. En el marco de la lucha contra del crimen organizado se hizo uso de los tres conceptos como si fueran sinónimos. Esto devino en la falta de coordinación en el diseño de la política pública de seguridad y tuvo implicaciones en el actuar de los responsables y operadores encargados de la seguridad, al establecer directrices que no terminan de brindar resultados eficaces. Ciudad Juárez es un caso que muestra la marquesina internacional de violencia y ausencia de Estado de derecho. 
Ciudad Juárez tuvo la experiencia de materializar los problemas de coordinación entre los tres órdenes de gobierno. El programa federal "Todos somos Juárez" fue muestra de lo anterior, a pesar de haberse trasladado los funcionarios federales a esta ciudad fronteriza. Al no tener claridad de si la lucha contra el crimen era un asunto de seguridad nacional o de seguridad pública local, se aplicaron modelos policiacos mixtos y poco conocidos.

Lo anterior derivó en la intervención del ejército nacional en funciones de cuerpos de seguridad pública, y la intervención de la policía civil en funciones bajo directrices castrenses. Todo se justificó en aras de preservar el Estado.

Dicha política de seguridad implementada en el marco del programa público "Todos somos Juárez" tuvo como consecuencia una violación reiterada de los derechos humanos y uno de los mayores fracasos de despliegue de cuerpos de seguridad.

Es necesario aprender de los errores. Por ende, surge la necesidad de distinguir tres dimensiones para comprender los modelos de seguridad y su aplicación. La seguridad es entendida de diferentes maneras en diversos contextos del mundo. Bárbara Holtmann (2010), afirma que en las comunidades que disponen de abundantes recursos, la seguridad es

...la habilidad de protegerse contra los riesgos conocidos; la aplicación de la tecnología y de la mano de obra contra las intenciones delictivas. En esta ocasión, la seguridad es utilizada para abarcar la "protección", la prevención, la reducción o la eliminación de estos riesgos en búsqueda de un entorno donde los ciudadanos ordinarios puedan vivir y desplazarse sin miedo (Holtmann, 2010: 1).

La finalidad de la seguridad es asegurar una situación de confianza, que no existan peligros o riesgos en el territorio de un país, tanto en sus estructuras, organismos públicos y privados y población en general frente a amenazas o agresiones que se presenten o puedan presentarse (Arteaga y Fuentes, 2009). 


\section{Los modelos de seguridad pública}

En primer orden, se aborda el modelo de seguridad nacional, el cual se personifica por los cuerpos militares con los que cuenta el Estado. Bajo un criterio erróneo los han incorporado a las funciones propias de cuerpos policiacos. Bajo el paradigma de la seguridad nacional surge la idea de orden interno, el cual se observa como un concepto de naturaleza esencialmente política, ya que es una directriz establecida por el Estado para regular sus interacciones con las instituciones nacionales, asegurando la estabilidad y permanencia de las estructuras del Estado y sus poderes, así como del sistema de gobierno legalmente constituido. El orden interno está pues enraizado en la teoría política.

Con las anteriores aseveraciones, es posible empezar a entender las características propias que tiene la llamada seguridad nacional, la cual, en nuestro país, cuenta con un soporte constitucional y una legislación secundaria propia encaminada a garantizar la permanencia del Estado frente a disturbios, ya sea derivados de invasiones externas o de movimientos internos hechos por nacionales que vayan en contra del Estado de derecho (Ferrajoli, 1995).

En México, y específicamente en Ciudad Juárez, la participación de la milicia dentro de operativos para preservar el orden público ha sido muy reiterada. El resultado de su actuar ha sido cuestionado por organismos protectores de derechos humanos, y es posible observar que las quejas en contra de elementos castrenses engruesa las estadísticas de abusos policiacos.

Otro modelo, el de Seguridad Pública, ha sido en tiempo actuales sujeto a discusión y estudiado por diversos académicos (Zaffaroni, 1974). La seguridad pública es "una cualidad de los espacios públicos y privados, que se caracteriza por la inexistencia de amenazas que socaven o supriman los bienes y derechos de las personas y en la que existen condiciones propicias para la convivencia pacífica y el desarrollo individual y colectivo de la sociedad" (García Ramírez, 2008).

Para lograr la tranquilidad de los ciudadanos, los cuerpos de seguridad dentro del marco jurídico se encargan de prevenir, investigar y ejecutar funciones dentro de un régimen de procuración e impartición de justicia. La seguridad pública se traduce, 
por tanto, en "una situación y un conjunto de presupuestos referidos a la tranquilidad, quietud y paz pública, como una necesidad básica de las personas y de los grupos humanos" (Malpartida Mansilla, 1999).

En tiempos más actuales, la seguridad pública se traduce en un derecho inherente al ser humano y una correlativa obligación hacia el Estado, ya que lo obliga a garantizar su tranquilidad mediante la prevención, en todos los ámbitos, que resulte en evitar situaciones de riesgo que contradicen un estado de armonía y paz. Los órganos estatales facultados para brindar la seguridad pública realizan su función mediante la prevención, investigación y sanción de las conductas antisociales. Cada uno en el ámbito de sus competencias y, estructurados bajo modelos de actuación, se proponen obtener la tranquilidad de los ciudadanos.

Bajo modelos recientes de actuación, el papel principal de brindar la seguridad pública recae en el órgano denominado policía. Este tiene la función de garantizar, mantener y restablecer el orden interno, que puede ser afectado por el accionar de delincuentes menores, por la delincuencia organizada y por el tráfico ilícito de drogas (Arteaga y Fuentes, 2009). El estado de impunidad que priva en diversos lugares del país ocasiona alteraciones sociales que ocurren diariamente en todas la latitudes del país. Son acciones que afectan al orden público y la tranquilidad de los gobernados, y su control y restablecimiento corresponden a los cuerpos de seguridad dentro de un régimen sujeto a la Constitución y las leyes y bajo la directriz de los derechos humanos.

El Estado moderno se materializa como el garante del bien común. En consecuencia, y derivado de la necesidad del lograrlo, debe poseer facultades de imperio por medio de la cuales esté legitimado para ejercer su autoridad en aras de organizar la vida social del país. De la necesidad de una seguridad para los ciudadanos, surgirá una función propia y específica del Estado, la cual se personifica en la función policíaca.

Bajo los parámetros establecidos en el ordenamiento jurídico, limitará las libertades consagradas en favor de los gobernados dentro del marco de la Constitución y el respeto a los derechos humanos, con el objeto de garantizar tranquilidad y paz a tra- 
vés de instituciones de carácter civil y con la meta de garantizar, mantener y restablecer el orden público.

El Estado necesita un órgano por el cual materializar su poder punitivo; dicha función recae en la policía. Independientemente de su competencia, mediante un modelo de acción y bajo parámetros de protección de derechos humanos tendrá como meta mantener una directriz responsable del poder policiaco.

En México, la seguridad pública asume una función de primera necesidad en favor de sus gobernados. Por ende, nuestra carta magna mandata, en su artículo 21, la coordinación de los tres órdenes de gobierno, instancias que componen la estructura política del país para interactuar en la prevención, investigación y persecución de los hechos delictivos. Con la anterior directriz, las tres esferas de nuestro Estado compuesto están obligadas a garantizar la seguridad pública de sus pobladores.

Los fines de la seguridad pública y de la seguridad nacional se distinguen claramente en función de los sujetos que cada una de esas funciones del Estado tutela. Así, la función de seguridad pública tiene la misión de proteger a las personas consideradas individualmente en sus libertades, integridad física y derechos patrimoniales. En el caso de la función de seguridad nacional, el sujeto tutelado es el Estado y su razón de existir es mantener la gobernabilidad de sus fronteras y preservar el orden, la paz y la tranquilidad de su población.

Las herramientas que utiliza cada modelo de seguridad se da por medio de las conceptualizaciones operativas. Por ejemplo, en el caso de la seguridad pública se habla de delitos e infracciones y para el caso de la seguridad nacional se materializan amenazas y riesgos.

\section{El modelo de seguridad ciudadana}

Acorde con la evolución de la sociedad y ante la necesidad de que esta asuma un papel activo en los tópicos de seguridad, emerge en diversos países un nuevo concepto de seguridad: la llamada seguridad ciudadana. Nuestro país no es ajeno al cambio; empero, es lento y muy gradual. En la actual constitución mexicana aparece todavía la denominación de seguridad pública y entre 
líneas aparece la participación ciudadana como secundaria. La nueva categoría conceptual, con el nombre de seguridad ciudadana, se traduce en una necesidad vital que debe tener una colectividad para que pueda desarrollar sus actividades sin temor a que exista un riesgo o amenaza a su integridad.

La seguridad ciudadana no desliga al Estado de brindar la tranquilidad con su fuerza policial, sino integra un personaje más en aras de lograr esa meta: el ciudadano, el cual participará desde su barrera contra la creciente diversidad de formas de criminalidad y violencia urbana que se producen particularmente en las ciudades. Es necesario tomar en cuenta las siguientes peculiaridades que forman parte del nuevo concepto de seguridad en mención:

1. La protección de los ciudadanos debe darse dentro de un marco de actuación y respeto de nuestra carta suprema y de la legislación secundaria. En este contexto, la seguridad ciudadana se constituye en un marco central para el desarrollo de los derechos humanos.

2. La seguridad ciudadana no se limita al combate contra la delincuencia, sino que busca crear un ambiente necesario para la convivencia de las personas por medio del desarrollo de mecanismos de cohesión social.

3. Los aspectos señalados permiten ver que la seguridad ciudadana rebasa la esfera de la acción de los cuerpos de seguridad y demanda, como requisito indispensable, la participación coordinada de otros organismos e instituciones, tanto del Estado como de la sociedad civil.

4. La seguridad ciudadana define y delimita la necesidad de un nuevo paradigma de policía, circunscribiéndola en un servicio de naturaleza civil orientado a la comunidad antes que proteger intereses del Estado.

5. Finalmente, la seguridad ciudadana pone mayor énfasis en el desarrollo de labores de prevención y control de los factores que generan violencia e inseguridad, antes que en políticas represivas o reactivas ante hechos ya realizados. 


\section{El protocolo de actuación policial en Ciudad Juárez}

El Estado mexicano pretende transitar hacia el modelo de seguridad ciudadana. Por tratarse de un modelo local, se hace necesario abordar un aspecto olvidado por muchos especialistas: el protocolo de actuación de la policía. A pesar de estar en presencia de un presupuesto fundamental, ya que el constructo de la seguridad deriva del procedimiento que marca la actuación policial, en nuestro país no es abordado con la importancia que amerita.

Es de vital importancia estudiar a profundidad bajo qué lineamientos jurídicos, sociales y operativos pueden llevarse a cabo los diferentes modelos de policía existentes y enfatizar la aplicación de los mismos en un territorio específico, como pudiera ser nuestra ciudad. Dichos lineamientos no están sujetos a la voluntad de los operadores del sistema jurídico, sino dependen de paradigmas específicos de la génesis de cada sistema policial.

En Ciudad Juárez, al igual que en varios municipios del país, es común que encargados de la seguridad pública tengan un discurso político que sitúa su modelo de policía bajo los criterios progresivos de la seguridad ciudadana. Desafortunadamente, dan por sentadas acciones que confunden el modelo policiaco de seguridad con el modelo de seguridad ciudadana. Se considera erróneamente que su actuar está regido por los lineamientos de una policía cercana, de proximidad ciudadana, cuando en realidad la acción policiaca responde a un protocolo policiaco de control represivo ante el probable responsable de la infracción y reactivo en cuanto al uso de la fuerza.

La palabra policía engloba cualquier cuerpo de seguridad pública. Se le ha asignado el significado de apego de los individuos a las leyes u ordenanzas, las cuales son instruidas por el Estado con la meta de llegar al bien común de sus agremiados. De lo anterior se observa la necesidad de contar con garantes que, bajo un matiz de protección de derechos humanos, vele por el cumplimiento de las leyes por parte de los ciudadanos y que se traduzca en realidad eficiente en cuanto a los resultados de la acción del Estado (Collado Medina, 2010).

La motivación de la actuación policial en un marco de Estado de derecho es central para contar con un cuerpo civil encargado 
de velar con profesionalismo por la seguridad de los ciudadanos. Lograrlo requiere determinar que la actuación de dichos cuerpos policiacos debe estar bajo el paradigma de legalidad en un sentido amplio, es decir, bajo las acotaciones que marcará el mismo ordenamiento jurídico con el fin de no transgredir la seguridad jurídica de los gobernados.

Dichas directrices estarán enmarcadas en disposiciones plasmadas en la Constitución Política de los Estados Unidos Mexicanos, así como en las legislaciones ordinarias que derivarán de dicho cuerpo legal y que en su conjunto serán el modelo a seguir por todas las instituciones de seguridad pública en México. Lo anterior implica que la actuación policial:

- Esté limitada a los derechos fundamentales o derechos humanos en aras de proteger un bien colectivo.

- Se legitime en tanto promueve el bienestar social.

- Pertenece al Estado (en un sentido amplio).

- Se plasmen las competencias en ordenamiento de toda jerarquía normativa, como la Constitución y leyes secundarias.

- Exista coordinación entre los tres órdenes de gobierno por mandato y bajo condiciones que la hagan posible.

\section{El marco normativo de la seguridad}

La fundamentación de la actuación de los cuerpos de seguridad en el Estado mexicano estará enmarcado dentro de la Constitución Política, artículo 21 que establece a la letra:

La investigación de los delitos corresponde al Ministerio Público y a las policías, las cuales actuarán bajo la conducción y mando de aquel en el ejercicio de esta función. El ejercicio de la acción penal ante los tribunales corresponde al Ministerio Público. La ley determinará los casos en que los particulares podrán ejercer la acción penal ante la autoridad judicial. La imposición de las penas, su modificación y duración son propias y exclusivas de la autoridad judicial (Constitución, 2016). 
La seguridad pública, en tanto función del Estado, se divide en competencias a cargo de la federación, las entidades federativas y los municipios. Hoy en día, la seguridad comprende actividades que van más allá de la vigilancia: 1) prevención; 2) investigación; y persecución; 3) sanción de las infracciones administrativas en los términos de la ley; y 4) la ejecución de pena en prisión. La actuación de las instituciones de seguridad pública se regirá por los principios de legalidad, objetividad, eficiencia, profesionalismo, honradez y respeto a los derechos humanos reconocidos en esta Constitución.

Por disposición constitucional, el modelo de policía no puede ser militar o militarizado, dado que las instituciones de seguridad pública serán de carácter civil, disciplinado y profesional. Bajo los tópicos actuales, no es factible que la seguridad de un Estado se sustente de forma única en la actuación de la policía. Empero, si se atiende al orden cronológico de actuación, se asume como primer eslabón en lo que se refiere a la cadena de procuración de justicia (Osorio y Nieto, 1999). En la mayoría de los casos, las actuaciones judiciales y legales que posteriormente se deriven de la conducta son motivo de su actuación.

En un primer plano, la seguridad comienza con la función policial. En efecto, en la mayoría de las latitudes del hemisferio, los cuerpos de seguridad pública encabezan en primer orden el mantenimiento y restablecimiento de la seguridad; es entendible que el modelo a aplicar tiene que ir acorde con la estructura jurídica del cada Estado. Siendo la policía la institución primaria y esencial para el mantenimiento de la seguridad, la forma en que esta se encuentre organizada y legalmente regulada va a adquirir especial importancia a la hora de conseguir su efectividad en el mantenimiento de la seguridad ciudadana. Se llega así a la noción de modelo policial, o modelo de seguridad, como conjunto de normas, instituciones, órganos, medios y procedimientos de actuación y coordinación entre todos ellos que tienen como objetivo garantizar la seguridad y la convivencia pacífica de los ciudadanos (Zazueto Betancourt, 2012).

Para enfrentar la criminalidad de un país se deben tomar como directriz diversos aspectos en aras de lograr el éxito y con- 
seguir mantener la seguridad. En primer lugar, la determinación de dicho modelo se obtiene después de un estudio profundo y metodológico y no surge de la nada sino que, como toda institución social, se va configurando paulatinamente, en consonancia con la estructura social en la que necesariamente tiene que estar incluido. Por ello, los modelos policiales y de seguridad de cada Estado se vinculan al sistema político, jurídico y social vigente en los diversos estadios históricos, e incluso al aspecto cultural.

\section{Clasificación de los modelos policiales}

El modelo policial o de seguridad es el esquema general al que responde el protocolo de actuación, despliegue y régimen estatutario de las instituciones encargadas de hacer cumplir la ley y preservar la seguridad de la comunidad, en la que desenvuelven su actuación profesional (Márquez , 1998).

Para comprender el modelo de policía aplicado, es necesario escudriñar las diversas clasificaciones que se plantean sobre la estructuración de la función policial. Se enfatiza que, ya en la práctica, la acción policiaca se materializa bajo diversas variantes; empero, cada uno tiene su propia sintaxis que le da peculiaridad. Su clasificación, de acuerdo con su función policial, es la siguiente:

\section{Modelo de control}

Es el modelo policial que está ligado a sistemas políticos que se caracterizan por violentar derechos humanos y su actuar atiende como principal preocupación la aplicación estricta de las normas. La función policial se materializa como el órgano del estado encargado del poder sancionador y represivo.

La actuación bajo el modelo en cuestión se desarrolla de forma inflexible con independencia de la naturaleza de las infracciones a las normas. Bajo un paradigma de control, la función policiaca se desarrolla mediante una estrecha vigilancia de las actividades de los ciudadanos, invadiendo esferas de la actividad privada y violentando de manera flagrante sus derechos. La actuación de los cuerpos de seguridad es mecánica y sin iniciativa propia, carente de discrecionalidad. En este modelo 
existe una gran presencia policial en las calles, y en algunas ocasiones, justificando la brutalidad policiaca con el pretexto de lograr tranquilidad para los ciudadanos.

2. Modelo de servicio público a la comunidad

Es un modelo policial complejo en el cual la función de los cuerpos de seguridad, tanto preventiva como de investigación, se desarrolla bajo el contexto protector del libre ejercicio de derechos fundamentales por parte de los ciudadanos. Además, establece un nudo entre la función policiaca y el desarrollo de las actividades de la comunidad; en este sentido, la seguridad de la cosa pública se vuelve una coproducción entre Estado y la ciudadanía.

Bajo el paradigma del modelo mencionado, en el marco de la interacción de la policía con la comunidad, el Estado realiza campañas de información sobre el accionar de los cuerpos de seguridad en aras de lograr una confianza en dicha institución y en la misma tesitura se aumenta la valoración de los ciudadanos y su confianza en la institución. La meta es lograr una imagen de cercanía y disposición de servir a la sociedad.

Los siguientes modelos se organizan de acuerdo con una territorialidad, siendo los siguientes:

3. Modelo político centralista

Este tipo de modelo se caracteriza por la existencia de una sola competencia encargada de brindar la seguridad pública en el Estado. Tiene como punto toral la dependencia exclusiva del gobierno central, es decir, maneja un estatus jerárquico en dependencia. La función de seguridad se concentra en una sola competencia para todo el territorio nacional, y a su vez bajo ese organigrama se realizan todas las funciones de policía.

4. Modelos descentralizados

Este tipo de modelo de actuación policial es propio de los Estados compuestos por entidades federales. El mantenimiento de la seguridad se encomienda a una multiplicidad de cuerpos policiales dependientes de las autoridades locales, estatales o federales y cada uno de ellos ejerce la función policial en el 
ámbito de sus competencias. Sus atribuciones legales están enmarcadas en las diversas legislaciones. Cada una de las instancias realiza la prevención y la investigación de hechos que posiblemente sean delictuosos.

En cuanto a su ámbito territorial de actuación, este se reduce al espacio territorial competente. Los detractores de este modelo comentan la falta de comunicación entre las instancias de gobierno, lo que origina problemas en el desarrollo de la función policial.

Los siguientes modelos se clasifican de acuerdo a la naturaleza civil o militar, y por ello, el modelo policial puede ser:

5. Modelo policial civil

Todos los cuerpos que lo integran son de naturaleza civil, es decir, no forman parte del ejército y cuentan con una carrera de profesionalización, promoción y ascensos.

6. Modelo de policía de tinte militar

En este tipo de modelo, su personal predominante es de preparación militar y por ende su actuar operativo adquiere una visión de práctica castrense.

7. Modelo policial de naturaleza mixta

Dentro del mismo cuerpo policial, coexisten cuerpos de naturaleza militar con otros de naturaleza civil. Los de naturaleza militar suelen tener una doble personalidad, pues cuando actúan como cuerpo policial lo hacen bajo principios de organización y funcionamiento de naturaleza civil. En cambio, cuando realizan tareas de índole militar lo hacen como una parte más del ejército.

8. La seguridad ciudadana en Ciudad Juárez

El gran reto del modelo de seguridad ciudadana es establecer parámetros de proximidad policial en la actuación de los cuerpos de seguridad. Lograr una efectiva aplicación de la seguridad pública por parte del Estado y una participación ciudadana en México, es un tema actual y centro de opiniones divergentes y de discursos recurrentes. 
Los índices de criminalidad que se desarrollan en nuestro país, y específicamente en Ciudad Juárez, forman gruesas estadísticas, pueden ser observadas en diferentes medios de comunicación y son tema central de cualquier reunión. Los discursos oficiales apuntan a manifestar que los cuerpos policiacos adoptarán ciertos modelos de actuación policial dentro de la comunidad, con la finalidad de brindar una mejor seguridad a los gobernados.

El modelo policiaco de moda se denomina "policía de proximidad", haciendo hincapié en que la implementación y aplicación correcta de dichos paradigmas de actuar de los cuerpos de seguridad impactará de manera palpable en los índices de violencia. La meta común es llegar, en esta transición, a la seguridad ciudadana.

Es necesario hacer un planteamiento de cuáles son las condiciones necesarias para que dicho modelo opere de manera adecuada y, en consecuencia, se logren las metas en las cuales sustentar su operatividad en Ciudad Juárez.

9. Del modelo de control hacia la policía de proximidad

La policía de proximidad, en cualquiera de sus vertientes, se ha convertido en un modelo de policía a seguir. Dentro de México, cada vez son más los distintos órdenes de gobierno que establecen en sus cursos de formación inicial parámetros de policía de proximidad. El lenguaje, la simbología y los programas propios de la policía de proximidad han aparecido rápidamente en la mayoría de los cuerpos policiacos en el país. Ciudad Juárez no es la excepción, y en tiempos actuales se prepara a los nuevos cadetes de la policía bajo los tópicos del modelo descrito.

El modelo policiaco de proximidad es un nuevo paradigma operativo para la mayoría de los cuerpos policiacos actuales. Sustenta su operatividad en el cambio de la relación entre la policía y el público, en dirigirse a los problemas subyacentes en la comunidad y mejorar las condiciones de vida de las ciudades en el aspecto de seguridad. Existen muchas perspectivas dentro de este tipo de policía y cada una de ellas se construye sobre presunciones que están solo parcialmente sustentadas 
por evidencias empíricas de los lugares del hemisferio en los cuales se han aplicado.

Los tópicos de la policía de proximidad sugieren que la aplicación de la ley puede ser más precisa, proactiva y sensible a la comunidad. Por otra parte, el modelo policiaco de proximidad obliga a la realización de importantes cambios en la organización social y formal. En cuanto a la organización social, se pretende que la policía de proximidad rompa las barreras que separan a la policía de los ciudadanos. En lo referente a la organización formal, se pretende que este tipo de policía cambie la forma de realizar su función, rompiendo los cánones rígidos de modelos tradicionales, que sustentan su actuar en la intimidación, buscando su lugar en un modelo que enfatice la función del policía como resolutor de problemas en un entorno de comunidad.

Las expectativas que genera un programa de policía de proximidad son muchas; entre ellas destacan: 1) el incremento de capacidad de las comunidades para prevenir el delito; 2) la creación de una relación armoniosa entre policía y ciudadanos; 3) la reestructuración del servicio policial, conectándolo con otras instituciones tanta públicas como privadas; 4) la reforma del modelo de organización policial; 5) y, finalmente, la creación de funciones más complejas y más amplias para el agente de policía.

Al analizar el nuevo parámetro policial, se visualizan agentes de policía más comprometidos, más analíticos y con poderes más amplios, además de jerarquías policiales horizontales. Este cambio también se convierte en objetivo principal de la prevención del crimen, por encima de la represión del mismo. Ciudad Juárez debe atender cambios profundos, para que la policía se transforme del modelo tradicional de control por el de policía de proximidad.

La adopción de la policía de proximidad requiere que esta sea un programa permanente, que cuente con cursos de formación inicial para los aspirantes a ingresar a las corporaciones policiacas y, en esa misma sintonía, aplicar las respectivas actualizaciones para los agentes ya en labor, abandonando la 
historia común en la mayoría de las urbes de nuestro país en lo que respecta a programas que se adoptan y son abandonados por los trienios de las administraciones.

Para que la policía de proximidad se arraigue, es necesario crear un nuevo ambiente de trabajo dentro de la corporación, que permita introducir nuevos valores de la policía de proximidad en la gestión y en las tácticas. La policía de proximidad debe superar la resistencia al cambio por parte los agentes en activo e incluso de la misma sociedad. La cultura policial en Ciudad Juárez tiene actualmente su eje de actuación en un enfoque de control. Es necesario tomar en cuenta dichas directrices, ya que al aplicar un nuevo modelo de actuación existirá reticencia al cambio derivado de una cultura policial tradicional que ha resistido con éxito y, de hecho, se ha impuesto a los intentos de transformación.

En la implementación de un nuevo modelo de policía, es indispensable observar qué efectos han tenido en la seguridad pública la aplicación de diversos modelos policiacos, pasando por la policía tradicional, la policía de tolerancia cero con sus características y presupuestos, hasta llegar a la nueva policía de proximidad. Las diferencias entre los distintos modelos permiten entender la evolución que ha sufrido la policía y los cambios de enfoque que suponen estos estilos opuestos.

Las bondades de un sistema de policía de proximidad son muchas, pero quedan en riesgo de permanecer solo en el discurso. En un intento por lograr una policía más responsable, que se aparte de modelos represivos, la policía de proximidad pretende generar un trabajo más eficaz en la lucha contra el delito y el desorden en las comunidades. Pretende, al mismo tiempo, eliminar las críticas sobre su ineficacia, ineficiencia e insensibilidad, que se remontan a tiempo atrás. La actuación de proximidad es el resultado del deseo de hacer a la policía más reflexiva acerca de su actuación en las comunidades para ayudar a mejorar los problemas del delito y del desorden.

El actuar de la función policial en México actualmente está sumida en continuas críticas e intentos de reforma. Desde sus orígenes, la institución de la policía ha sufrido diversas modifi- 
caciones en su actuar. Si se hace un estudio de la misma, tendremos que lamentar que los modelos policiacos en México sean producto de las políticas de seguridad pública implementadas, matizadas por el momento político vigente, carentes de toda organización y operatividad y, en consecuencia, sin una directriz metodológica. La policía es el elemento más visible del gobierno para la sociedad civil, y lamentablemente se ha transformado en un bastión simbólico y fundamental de negociación política y de violencia ilegítima del Estado.

En la actualidad, el tema de seguridad pública es una función estratégica en los asuntos públicos del país. Desde tiempos remotos, en su afán de protegerse de las inclemencias de la naturaleza, de los animales y de otras personas, la sociedad organizada tomó medidas preventivas y otorgó al Estado la función de vigilancia y seguridad del entorno ciudadano.

Las ciudades seguras constituyen hoy en día una aspiración ciudadana que se debe traducir en mayor tranquilidad y bienestar. La seguridad es también uno de los principales factores que tienen incidencia sobre la calidad de vida de las personas. Cada nación ha generado mecanismos institucionalizados para salvaguardarla, ya que constituye un derecho universal equiparable a la salud, la educación, la vivienda y el trabajo.

Por tanto, el concepto de Estado tiene la función irrenunciable de salvaguardar la seguridad pública, por tratarse de la organización jurídico-política de la sociedad que detenta el monopolio de la violencia legítima del Estado. El fin supremo de la sociedad y del Estado es la protección de la persona humana y el respeto de su dignidad; una de las formas de garantizarla es a través de la seguridad.

Actualmente, la seguridad constituye una de las principales prioridades de los gobiernos y sociedades para lograr su desarrollo y consolidación. En México, esto se ha materializado por medio de sendas reformas a nuestra carta magna, que se visualizan específicamente en la parte dogmática del ordenamiento supremo.

Ciudad Juárez no es la excepción, y en aras de lograr un ambiente de certidumbre y tranquilidad para sus habitantes, ha 
desarrollado en su devenir histórico diversos constructos de seguridad pública que buscan cristalizar ese derecho humano por excelencia.

\section{EPÍLOGO}

La eficacia con la cual se mueve la policía de Juárez hacia resultados basados en un modelo de proximidad requiere mantener el control de la corporación bajo mandos operativos civiles. La naturaleza de las fuerzas militares no admite ningún control que no sea la jerarquía militar el mando supremo, entiéndase Presidente de la República o Secretario de la Defensa Nacional.

Los controles sociales a través de organizaciones de la sociedad civil requieren fortalecerse para transitar a una policía basada en políticas de seguridad ciudadana. Para ellos es indispensable conocer el desarrollo de una política de seguridad en la cual se conceptualice cada institución policiaca en términos operativos.

Los titulares de la corporación de policía están más que obligados a distinguir qué tipo de seguridad se está aplicando en un tiempo determinado, y evitar confundir enfoques que no guarden relación con la proximidad. Como consecuencia de lo anterior, se vuelve requisito indispensable el conocer las estructuras de los diversos modelos policiacos que están íntimamente ligados con el tipo de seguridad que se pretende proveer. Por ende, para lograr una seguridad es necesario la cohesión con la estructura que va a asumir la función policial en tiempo y espacio, ya que de ella dependerá el éxito de su encomienda.

La meta de alcanzar una seguridad más ciudadana por medio del ejercicio de la seguridad pública del Estado, solo es posible mediante la participación ciudadana. Es necesario reconocer que el actual modelo represivo de la función policial en México está agotado. Desde sus orígenes, la institución de la policía ha sufrido diversas modificaciones en su actuar, primero como policía administrativa y ahora como policía represiva. Si se hace un estudio de la misma, tendremos que lamentar que los modelos policiacos en México son producto de las políticas de seguridad pública matizadas por el momento político vigente, carentes de 
toda organización y operatividad y, en consecuencia, sin una directriz metodológica o sin protocolos completos dados a conocer a la ciudadanía.

La policía es el elemento más visible del gobierno para la sociedad civil, lo que hace central transformarla a partir de una propuesta simbólica que aterrice en un modelo de seguridad que brinde resultados eficaces y eficientes. De ahí que procesos de certificación sean clave para revivir la poca confianza que aún se tiene hacia cuerpos de policía de parte del ciudadano.

La policía en México se ha ido desarrollando como un edificio construido sin planificación. Es necesaria una revisión sobre los cambios en la estrategia policial. En este sentido, la policía debe dejar de preocuparse principalmente por el mantenimiento de las relaciones políticas, en muchos casos corruptas, y de aplicar abusivamente la ley. Debe cambiar una dinámica que venía desarrollándose por muchos años. Pasar al siguiente estadio, en el cual la función policial se debe ver reflejada en el modelo de proximidad, requiere de protocolos y profesionalización de los y las agentes, no solo de capacitación.

La obligación del Estado mexicano de brindar seguridad a sus ciudadanos en la actualidad, no puede ser de manera arbitraria y conculcando los derechos humanos en aras del bien común traducido en seguridad. La cultura policial en México debe transformarse y la policía de Ciudad Juárez no es la excepción. Abandonar el modelo de control represivo se justifica ante la brutalidad policiaca llevada a cabo bajo el ejercicio del manto protector del Estado que garantiza mantener la paz.

Cambiar a un modelo de proximidad, de control social, que como se esbozó en líneas anteriores, conduce a una mejor sinergia entre los cuerpos policiacos y la sociedad, se logrará mediante la implementación del modelo de proximidad bajo condiciones de cohesión entre los diferentes actores, organizaciones de ciudadanos y la policía, tomando en cuenta la necesidad de que las autoridades se aparten de modelos utópicos de actuar y centren sus recursos en un modelo práctico que necesita la aplicación en un contexto de violencia latente. 
En el mundo existen muchos casos de estrategias exitosas en materia de prevención, tales como las realizadas en las ciudades de Bogotá y Medellín, Colombia; Belo Horizonte y, últimamente, Río de Janeiro, Brasil (Moore, 1994).

Incluso, en un país de vasta extensión territorial como México es necesario un planteamiento metodológico sobre el actuar de la función policía en aras de lograr la seguridad anhelada. Las tendencias tradicionales de someter las prácticas policiacas a directrices partidistas son un aspecto muy común en nuestro país y municipio. Estas se apartan de metodologías propias de la función policial y se centran en buscar un beneficio personal o de partido. La designación de jefes militares como jefes de seguridad pública es una mala praxis que ha ocasionado la imposibilidad de aplicación de un modelo de proximidad.

El mando castrense aplica su disciplina en sus subalternos y opera en Estados de excepción, sin garantías ni derechos humanos que respetar, salvo cuando su actuación se enmarca en planes de acción como el DN-III-E, de protección civil.

Que el Estado recupere a la policía en su vertiente administrativa y de prevención (Landaeta et al., 2015: 95), es fundamental y para lograrlo se requiere ejercer funciones policiales desde la representación política civil y, en consecuencia, también el mando operativo exige experiencia de un civil al frente.

No se puede ignorar la falta la profesionalización, así como la corrupción de mandos y agentes, la falta de liderazgo y de responsabilidad de los operadores del sistema de seguridad, como problemas arraigados y que dificultarán la implementación de controles sociales y el enfoque de proximidad en la actuación policial.

La seguridad pública en México y en Ciudad Juárez se sustenta en operativos muy empíricos, que desconocen los paradigmas y protocolos de proximidad en la actuación de la función policial. Los procedimientos para la selección del personal policiaco y elaboración de un perfil sólido de ingreso dirigido a lograr la operatividad del modelo de proximidad, implican atender lo siguiente:

- Escolaridad mínima para ingreso a la policía. En la mayoría de las policías municipales de México, y específicamente en 
Ciudad Juárez, el nivel académico para ingreso y permanencia en cuerpos de seguridad pública está en secundaria. En consecuencia, es imposible una capacitación teórica sobre dispositivos legales y reglas de actuación policial necesarios para la función policial y su coexistencia con la sociedad.

- Creación de incentivos sobre permanencia y un sistema sustentable de ascensos. En la actualidad, la mayoría de las personas que ingresan a una corporación policiaca la visualizan como un refugio ante la falta de trabajo. Aunado a lo anterior, una vez dentro del sistema observan la ineficacia de un servicio de carrera policial que los incentive y que les garantice su estatus y permanencia dentro de la corporación.

- Sistemas de inteligencia y de diagnóstico criminal y cooperación entre los diversos cuerpos de seguridad pública.

- Rehacer vínculos de confianza entre policías y ciudadanos. Desde la academia de policía se debe trabajar en la formación de este perfil basado en la confianza y habilidades de investigación para la solución de problemáticas.

- Monitorear y dar seguimiento a los agentes de policía que egresaron del programa de proximidad; conocer su desempeño, que debería ser eficiente e innovador.

Como se observa, lograr un modelo sustentable y de proximidad en seguridad ciudadana en Ciudad Juárez es un camino de larga marcha. Se necesita vencer la resistencia al cambio. Esta viene desde los mismos policías operativos, empero, es necesario hacer una nueva reingeniería de la función policial en aras de lograr un estado de tranquilidad para los ciudadanos.

Lograr la transición hacia una seguridad ciudadana basada en la proximidad y cercanía policial implica enormes retos, que deben atenderse en investigaciones académicas y en investigación aplicada desde la participación de la sociedad civil especializada. Actualmente, se hacen esfuerzos innovadores de certificación del cuerpo de policía por organizaciones de la sociedad civil. De su resultado se abren futuras líneas de investigación y se dibujan futuros retos, como el focalizar un programa sustentable de largo plazo, producto de la certificación. 


\section{REFERENCIAS BIBLIOGRÁFICAS}

Aguirre, L. (2014) "Visiones de la esperanza: recuperación de espacios públicos y generación de actividades comunitarias en Ciudad Juárez". NÓESIS, Revista de Ciencias Sociales y Humanidades. Vol. 23, número 46, semestre julio-diciembre. Ciudad Juárez: UACJ.

Arteaga, N. y Fuentes, R. (2009) "Nueva lógica de la seguridad en México: Vigilancia y control de lo público y lo privado". Revista Argentina de Sociología. Año 7, No 12 / No 13, pp. 164-18.

Collado Medina, J. (2010) La investigación criminal y sus consecuencias jurídicas. España: Dikison.

Constantino, H. (2016) Policía de proximidad. Tesis para obtener Licenciatura en Ciencias de la Seguridad. UACJ. Mimeo.

Ferrajoli, L. (1995) Derecho y razón, teoría del garantismo penal. Madrid: Ed. Trotta.

García Ramírez, S. (1994) Las andanzas de la seguridad pública. Academia Mexicana de Ciencias Penales-Porrúa.

García Ramírez, S. (2008) "En torno a la seguridad pública. Desarrollo y evolución del delito” en Peñaloza y Garza (eds.). México: Universidad Iberoamericana, UNAM, PGR.

Holtmann, B. (2010) "Palabras de la presidenta del CIPC", en Informe internacional sobre la prevención de la criminalidad y la seguridad cotidiana: tendencias y perspectivas. Canadá: Centro internacional para la prevención de la criminalidad.

Landaeta, Arias y Espinoza (2015) "La función de la policía como debate de libertades", en Eidos, revista de Filosofía, número 23, semestre agosto-diciembre, pp. 93-116. Bogotá: Universidad del Norte.

Malpartida Mansilla, A. (1999) Derecho positivo y diseño doctrinario del orden interno, Lima, Perú: Distribuidora Buenaventura, Luna.

Márquez, T. G. (1998) Modelo policial y forma de Estado en España. España: Atelier Libros.

Moore, M. (1994) "Research synthesis and policy implications", en Ronsebaum (ed.), The challenge of community policing: testing the promise. California: Thousand oaks.

Oseguera, A. (2016) "Las ciudades imposibles. Violencia, miedos y formas de militarización contemporánea en urbes latinoamericanas: Me- 
dellín-Ciudad Juárez", en Frontera norte vol. 28 no. 55 México enerojunio, 2016.

Osorio y Nieto, C. (1999) Seguridad pública y procuración de justicia. México: Criminalia, Academia Mexicana de ciencias Penales, Porrúa.

Reporte (2010) "50 ciudades más violentas del mundo". Consejo Ciudadano para la Seguridad Pública y la Justicia Penal, AC. México, DF.

Reporte (2015) “50 ciudades más violentas del mundo". Consejo Ciudadano para la Seguridad Pública y la Justicia Penal, AC. México, DF.

Reporte (2016) “50 ciudades más violentas del mundo". Consejo Ciudadano para la Seguridad Pública y la Justicia Penal, AC. México, DF.

Zaffaroni, E. R. (1974) Tecnificación policial o pensamiento mágico. Criminalia, Academia Mexicana de Ciencias Penales-Porrúa.

Zazueto Betancourt, J. A. (2012) La inseguridad y seguridad ciudadana en América Latina. Clacso. 